\title{
The Enactment of Teacher Collaboration in Innovative Learning Environments: A Case Study of Spatial and Pedagogical Structuration
}

\author{
Chris Bradbeer
}

\begin{abstract}
Implicit within the design of many Innovative Learning Environments (ILEs) in New Zealand primary schools is the intention of a group of co-located teachers working together with an 'up-scaled' community of students. To some these socio-spatial settings are suggestive of pedagogical and spatial freedom, of high levels of professional and student agency, and a transformation away from routines established in previous traditional classroom environments. The shift into ILEs may therefore encourage possibilities for novel approaches, the utilisation of individual strengths and opportunities for teachers to determine together how facets of learning, time and space are organised. However, the level of structure required by teams to successfully and collaboratively achieve this presents as a complex, and time-consuming task, with teachers often finding themselves in a space between practicality and potential. This paper draws on observational and interview data from one primary school ILE - part of a wider case study of teacher collaboration in six New Zealand schools. It considers the role of pedagogical and organisational structures alongside levels of autonomy experienced by teachers on adapting to new spaces. The findings indicate that while the occupation and ongoing inhabitation of Innovative Learning Environments may well present opportunities for teachers, tensions may be felt between predominating or created structures, and aspired or idealised practice.
\end{abstract}

\section{Introduction}

The development of Innovative Learning Environments (ILEs) (OECD, 2013) and Flexible Learning Spaces (Ministry of Education, 2011) in New Zealand schools presents a significant shift in educational discourse and school space design. Conceptualised as progressive and relevant socio-spatial assemblages for contemporary approaches to learning and teaching, ILEs and the pedagogical affordances they offer are considered to more readily support diverse requirements of 'twenty-first Century

C. Bradbeer $(\varangle)$

The University of Melbourne, Melbourne, Australia

e-mail: chris.bradbeer@unimelb.edu.au

W. Imms and T. Kvan (eds.), Teacher Transition into Innovative Learning Environments, https://doi.org/10.1007/978-981-15-7497-9_5 
learners' than traditional classroom-based environments. Hence, their systematic rollout (Bradbeer et al., 2017) is intended to contribute to the Ministry of Education goals of raising student performance and outcomes (Ministry of Education, 2011, 2016). This alignment of pedagogical intentions with spatial design has resulted in the development of up-scaled primary school spaces containing zones attributed to activities such as presentation, making, collaboration and reflection; as well as settings for both individual and group learning (Dovey \& Fisher, 2014; Fisher, 2005).

In the transition into ILEs, it is apparent the spatial and pedagogical shifts required have been demonstrated to demand new competencies of teachers, whether in adopting new pedagogical approaches or in navigating new and up-scaled spaces (see for example Alterator \& Deed, 2013; Cleveland, 2011; Cox \& Edwards, 2014; Deed \& Lesko, 2015; Deed, Lesko, \& Lovejoy, 2014; Saltmarsh, Chapman, Campbell, \& Drew, 2015; Woolner, Clark, Laing, Thomas, \& Tiplady, 2012). Research has drawn attention towards the way that teachers are required to demonstrate adaptability in these situations, and to 'question classroom convention and routine' (Alterator \& Deed, 2013 p. 327).

In addition, and notwithstanding the significance of these changes, teachers in ILEs are anticipated to work communally and collaboratively. Identified as leading to a higher degree of pedagogical variation, professional learning and teamwork (OECD, 2013), this mirrors a more general initiative towards engendering higher levels of collaborative professionalism within education and schools. Architecturally this intention is often explicitly articulated; larger spaces designed with larger cohorts of teachers and students in mind, and an absence of individual traditional classrooms where teachers have historically experienced considerable autonomy. Pedagogically though the enactment of effective collaborative practice within ILE appears less well understood. For many teachers it is this aspect of the move into ILE that may constitute the most significant transition on the professional landscape, and one that will entail considerable navigation and negotiation. It is in this space that the present study is situated, with a purpose towards focusing on how one team of teachers conceptualised pedagogical and spatial structures within an ILE.

\section{Teacher Collaboration}

The fostering of deeper levels of multilevel collaboration has long been considered instrumental in leveraging large-scale shifts in students' educational outcomes (Fullan \& Langworthy, 2014; Goddard, Goddard, \& Tschannen-Moran, 2007; Hattie, 2015; Stoll, Bolam, McMahon, Wallace, \& Thomas, 2006). Much of this success is attributed to the reduction of teacher isolation, increased motivation and morale (Vangrieken, Dochy, Raes, \& Kyndt, 2015); in turn leading to higher levels of Collective Teacher Efficacy (Donohoo, 2017; Eells, 2011). However, as Hargreaves and 
O'Connor (2017) determined, the level and relative success of collaborative strategies has ebbed and flowed through recent educational history, resulting in the conclusion that, 'not all forms of collaboration are equally strong, desirable, or impactful' (p. 77).

Considered to be a step above situations of cooperation and coordination, collaboration is definitionally concerned with giving something up for the greater good in order to achieve something that is not possible individually (Gray, 1989; Thomson \& Perry, 2006). Incumbent within this is a level of formal commitment, planning and organisation towards a commonly held mission, a factor that inherently requires the relinquishment of some individual autonomy and a proportional level of risk to personal reputation (Mattessich, Murray-Close, \& Monsey, 2001; Peterson, 1991). Here, and following Hoekstra, Korthagen, Brekelmans, Beijaard, and Imants (2009), autonomy is taken as a degree of control over one's own environment. To successfully accomplish this, the process of collaboration identified by Wood and Gray (1991) outlined a need for shared rules, norms and structures, a clear intention towards action, and a shared orientation towards the purpose that brought people together in the first place. Furthermore as Thomson and Perry (2006) concluded, although the collaborative process required structures in order to make decisions and to manage ways of working, parallel attention to participants' autonomy is needed so that individual identity could be retained, strengths utilised and mutual benefits recognised.

For teachers the literature is unapologetic in arguing that collaboration requires a re-imagining of sometimes long-held teaching identities, a redefining of established 'rules' of teaching, and various degrees of sacrifice of autonomy. An obvious tension therefore surrounding the application of collaborative principles into the context of ILEs is how they might be enacted. That the relative success of an ILE is dependent on strong collaboration between teachers appears obvious, yet its form may present outside many teachers' professional experience.

Furthermore, when examined from a spatial perspective, scenarios of teacher collaboration are often revealed to have taken place outside the classroom with collaboration more usually practiced as a 'visited activity' (Forte \& Flores, 2013; McGregor, 2003). More likely, collaborative professional activities have taken place in the staffroom, team meeting or faculty office (McGregor, 2003). In the discourse regarding the transition of teachers into ILEs, the enactment of teacher collaboration from a spatial perspective therefore appears something of an absent presence; it appears underresearched and under-theorised, yet provides a lynchpin underpinning the prospective success of ILEs.

\section{Teacher Collaboration in ILE: The Need for Structure}

A consistent theme through the literature on collaboration is the balancing of individual autonomy with structures required to ensure that collaboration works. For many teachers this may present as new learning, in particular when related to concessions of time and space. Historically, within the traditional classroom situation, 
the establishment and operationalisation of organisational structures such as daily routines, student grouping, time allocation and spatial practices have largely remained under the jurisdiction of relatively autonomous individual professionals (Clandinin \& Connelly, 1996). In contrast, and implicit in the move into ILEs, is that team-teaching, sharing of resources, space, distribution of roles and pedagogical organisation will occur (Saltmarsh et al., 2015). Frequently this takes place with larger numbers of students than previously encountered in a classroom setting. For example, Campbell, Saltmarsh, Chapman and Drew (2013) observed a learning environment designed for 75 students and three teachers to note a need for teachers to demonstrate 'willingness to try new things' and to 'take responsibility for their designated tasks' (p. 219). With similar numbers in a high school context Cox and Edwards (2014) observed how timetabling was employed to schedule blocks of subject learning, alongside ability grouping of students; 'this organisation was viewed as a more effective use of the space and more manageable for teaching' (p. 69).

In their case studies Saltmarsh et al. (2015) determined that teachers operating in ILEs appeared to navigate a fine line between the relative levels of structure (or not) in realising responsive pedagogies. They identified a tension between a desired need for innovation and flexibility, alongside the creation of an environment that was ordered enough for learning, that enabled teachers' 'demonstration of professional competence' (p. 324). In their observations they found that 'teaching teams reliant on an over-emphasis on structure and order at times experienced considerable difficulties in achieving the learning goals they had set out' (p. 325). An additional structural tension appears to be in the form of applying previously successful modes of operation into new environments. For Deed and Lesko (2015) although the relative openness of ILEs signified what they refer to as a 'physical and social unwalling of authority and routine' (p. 220) the capacity for teacher adaptation to remain hampered by institutional memory and previously adopted routines remained strong.

In contrast to historically persistent portrayals of classroom teaching as a lonely and isolated profession (Butti, 2016; Lieberman \& Miller, 1990; Little, 1990), ILEs represent anything but. The re-scaling of school spaces brought about by the development of ILEs brings teacher collaboration into the front and centre of attention. While a wealth of literature informs challenges and supports the development of collaborative teaching practice, what is noteworthy is the seeming lack of any spatial perspective in this research. For this reason, the case study focuses on describing a set of practices established in a Year 7-8 ILE with a team of three teachers.

\section{The Case Study: Treeside Intermediate}

The case study research, part of a wider three-phase Ph.D. study examined the intersection between teacher collaboration and one ILE. The research used a qualitative, collective instrumental case study design (Stake, 1995), so that the issue became the focus rather than the group being studied. Data in this case was collected through observations, semi-structured interviews with the principals and focus groups of 
teachers and students. It was analysed using thematic narrative analysis (Riessman, 2008), and interrogated through the lens of the theorisation of collaborative process (Thomson \& Perry, 2006). The data presented in this paper was gathered from one of the Phase 2 sites, Treeside Intermediate.

Treeside Intermediate is a suburban Year 7-8 school built originally in 1976 with a student roll of 290 . The school was divided into three 'communities', each occupying a building (recently refurbished on a tight budget), containing a set of rooms (previously individual classrooms), aside from a central 'corridor'. The move into communities had been a relatively recent change prompted by a desire to create a more collaborative teacher culture, and a consideration of how space across the school might be more optimally utilised. The principal reflected that the spatial changes had resulted in a feeling of calmness through the school, and a sense of excitement among teachers to explore what was possible in a new team setting. Within their communities, teams had been given a high level of autonomy to decide how they would operate. Pivotal to the school's vision was the idea of building agency and self-management skills in students, something regularly reinforced through a schoolwide set of values. Students were encouraged to take responsibility for their actions, learning and relationships, as well as to feel proud of who they were and what they had achieved.

\section{Findings: Pedagogical, Spatial and Collaborative Practices}

The Whio community of learners was home to 94 students. It was staffed by three teachers, (one a 'beginning teacher'), and a teacher aide who worked predominantly with students requiring additional support. At the beginning of the year the teachers acknowledged that they had mainly worked individually with their own 'class', but over the first term had identified ways in which they could work more closely as a team, play to their strengths, and better build levels of self-management with students. They had subsequently divided curriculum responsibilities so that two teachers were responsible for teaching literacy to ability groups across the whole cohort, with the third teaching all the mathematics. Teachers were largely responsible for designing learning and selecting resources for their particular groups. This approach was considered by the team to be pedagogically advantageous as well as a means of creating organisational efficiency. Of concern to teachers under the new structure was over how well they would 'know' individual student's learning across the curriculum, particularly when it came to having conversations with parents. They also noted it reduced their ability to respond spontaneously to learning opportunities and to take more time than had been allocated. However, teachers considered that the new approach had shifted some management emphasis onto the students to ensure they were in the right place at the right time for particular learning groups and activities, something that was supported by a regular routine and reminders in the form of centrally placed timetables. Additionally, this required the students to navigate a structure of spatial usage. 
The four rooms adjacent to the central passageway had been named, assigned specific usage and furnished accordingly (see Fig. 1). Room 1 was designated as the Quiet Space, and minimally furnished with only a few tables and chairs. In here, 'you can whisper to your buddy, but not loud talking' (Isobel, Year 8). The lack of furniture meant that students often sat on the floor, but it enabled the same room to also function as the larger team meeting space, used particularly to begin the day. Room 2 (Paired Space) was allocated for students to work in pairs and was furnished with tall tables and stools. Room 3 was set up as the Teaching Space, furnished with a whiteboard on one wall with a set of tables in front of it (for one teacher), and on the other side of the room a teaching station with soft seating around it (for another). In addition, a row of individual desks ran down the outside wall on both sides, facing the front. It was in here that the two teachers teaching literacy or mathematics groups at any one time were based. As one teacher commented: 'The kids know their timetable, and they just come to us. We'll just stay in the room. If we've got two lessons in a row, I'll just sit there all morning and they'll come to me' (Nick, teacher).

Room 4 was referred to as the Group Space furnished with tables and chairs designed for small group use. Additionally, a centrally located workspace provided a meeting and storage space for staff. Internal glazing meant there was visibility into Rooms 1 and 2, and to the central passageway. Previously set up as a small science room, teachers and school leaders noted that removing teacher's desks from classrooms and collocating into a shared space had been a deliberate move towards decreasing ownership of space, and the creation of a more collaborative workplace.

Fig. 1 Spatial layout and designation in 'Whio' community

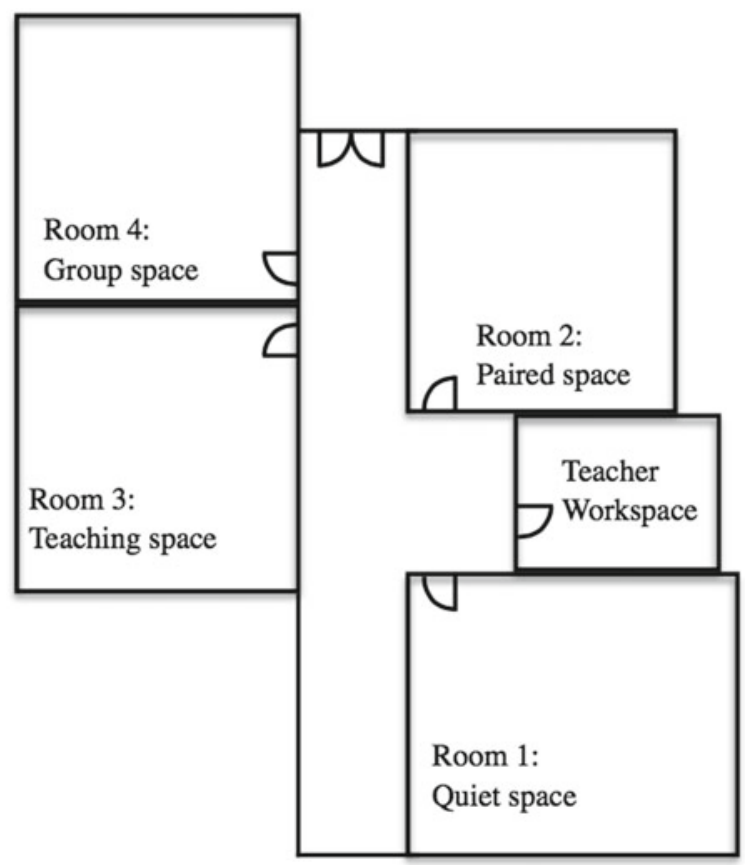


Teachers viewed it as a key assemblage. It often formed a place for formal and informal meetings during the course of the day. Material evidence of their collegial activities was apparent in a series of Polaroid photographs suspended on a string across the room, these being taken on school trips, during team-building sessions and within the community.

The opportunity for one or two teachers to remain in the Teaching Space for any duration was enabled through a set of co-constructed team protocols. Students were assigned activities following maths and literacy sessions that they were expected to complete either individually or with a partner. In addition, a weekly activity sheet contained a number of 'must-do' and 'can-do' tasks. For some students these tasks were differentiated, and support made available from the teacher aide. An established norm within the community was that students knew not to disturb teachers who were engaged working with a group. Instead the expectation was that they would talk to the third teacher, the roaming 'Learning Coach' for assistance. The Learning Coach's role was to respond to queries from individual students, monitor levels of self-management and independence, as well as to 'sign-off' completed activities on the weekly sheet. The practice provided immediacy and timeliness of support that students felt would be lacking if they were all teachers were working with groups simultaneously. As one of the students reflected, 'it's really good because all the time there's a teacher roaming in our block, so you can always ask for help. You're never alone to do your work' (Wiremu, Year 8). Observations distinguished that the Learning Coach's mobility (and that of the teacher aide) was in strong contrast to those teaching in the Teaching Space.

For individual students, their opportunity to use the different spaces in Whio was determined through a perceived measure of their level of self-management. This was mediated through the 'Independence Wall' and applied the language of SOLO (Structure of Observed Learning Outcomes) taxonomy of learning (Biggs \& Collis, 1982) to levels of individual independence. Used primarily across the school as a meta-cognitive framework to describe levels of understanding, teachers in the community had adapted it to this context. Students' positioning on the display board contributed directly to their levels of permissible spatial access. Decided by the teachers, the further to the right their photograph was placed on the display, the greater the range of spaces accessible to them. Consequently, some students were limited to staying in a room with their 'home-room' teacher, while others were able to work away from direct supervision from any teachers, and ultimately to have the freedom to work anywhere through school. During one observation two students moved a small table into the broader central corridor to work together. On noticing, the Learning Coach asked them to move it into the Quiet Space instead. Subsequent questioning explained that only one of the students was able to select to learn in any part of the community, hence they had been asked to move. Teachers acknowledged that opportunities for spatial independence provided a level of incentive for many students.

The development of collaborative forms of working (including the use of synchronous and asynchronous online documentation), had formed a significant investment for the team of teachers in Whio, including the scaling-up of a number 
of routines that were required over and above those required by teachers working on their own. Much like Saltmarsh et al. (2015) had identified, the need to spend time together had placed some constraints on teachers. Collaborative decision-making together had been, 'definitely not something you can rush' (Helen, teacher). Planning, and consideration of how the community was going to function on a day-to-day basis had occupied much of their time. Similarly, time dedicated towards meeting each other during the week, to reflect on, and adapt practices to suit their new arrangement was acknowledged as having been considerable and ongoing.

\section{Discussion: Towards Structuration as Enactment of Teacher Collaboration}

For the experienced teachers in the study, colocation with colleagues in shared spaces represented a significant departure from their previous spatial experiences within schools. Similarly, for the teacher new to the profession it was appreciably different from the spaces she had trained in and had prepared for. For both, individual classrooms had represented jurisdictional domains, where teachers were relatively free to set structural frameworks (Clandinin \& Connelly, 1996). Much as Saltmarsh et al. (2015) had previously concluded, it was evident that there was a high level of organisational sophistication, professional inquiry and collective learning in this shared learning environment that, had teachers been working on their own, would not have been required. In this case much of the need for organisational sophistication appeared concerned with the enactment of teacher collaboration.

Central to the model of collaborative process posited by Thomson and Perry (2006), is the development of structures with which to facilitate decision-making, and reach 'agreement on collaborative activities and goals through shared power arrangements' (p. 24). In this case, through their collaborative process, teachers had created a way of working that would support the enactment of teacher collaboration at the interface with students, and at the same time signalled a shared intention towards action and orientation (Mattessich et al., 2001). Emblematic of 'giving something up for the greater good', and achieving something that was not possible individually (Thomson \& Perry, 2006), here the 'greater good' was determined to be a set of values and learning outcomes that could perceivably be better achieved through teachers working in modified spatial settings. In so doing, initial establishment and ongoing maintenance of these through the collaborative process had appeared to require the relinquishment of some individual autonomy (Peterson, 1991). Decisions that teachers might in the past have made about the use of time and space were now negotiated with colleagues. However, the team at Treeside Intermediate had been given a high level of decision-making autonomy to develop an approach to achieve what they were ultimately aiming for; the development of student agency and self-management skills. Consequently, teachers considered the resulting limitations to individual professional autonomy as accepted limitations. Furthermore, 
although teachers expressed the idea that some aspects of their agency were limited by the structures in place, (generally articulated in conjunction with aspects of the curriculum, being able to communicate broad knowledge of individual learners with parents, or capacity to be pedagogically responsive in the face of temporal boundaries), they did not necessarily see it as overly problematic. What they considered they could achieve together outweighed the perceived disadvantages. Data also suggested that the professional culture of inquiry and improvement within the team of teachers also allowed room for ongoing refinement and redesign of practice over time. This is suggestive of Hargreaves and O'Connor's (2017) reflection that collaborative cultures were characterised by trust, openness about problems, independence, collective effort and shared responsibility. In time, perceived limitations could and might be addressed.

The team of teachers in Whio community had developed an assemblage of temporal and spatial structures that deliberately articulated and reinforced organisational routines and pedagogical practices. Routines to encourage both agency and selfmanagement were operationalised and accomplished within boundaries of behaviour and well-defined parameters. Teachers' use of time and space was strongly governed by those parameters and included limits on time spent with student groups, the requirement to adhere to timetables and responsibilities, and the need to meet regularly to collectively make decisions. Additionally, teacher spatial mobility depended on the role they were playing; in turn the level of mobility they permitted students was similarly dependent on an additional structural framework. Taken together, these structures were viewed as means to enact both school-wide intentions, conceptualised in terms of developing levels of learner agency and self-management, and to respond to the needs of the current cohort of students. In addition, they were considered by participants to support the transition of teachers and students to new ways of working. Specifically, the practices and structures teachers employed also ensured that they maintained a level of control over a larger cohort of students while at the same time theoretically providing room to develop more self-managing skills among them. Here there appears a fine line between agency, self-management and the requirements for structures in 'amplified' (Alterator, 2015) environments, that may in turn conjure images of Foucaultian control mechanisms. Justification for this was connected with the idea that intermediate schools are '80-week schools' (Principal), and that there is a need for the quick establishment of expectations and routines. A useful next research step could be in understanding the type of agency afforded in Whio community in conjunction with the school's idealised vision. Engagement with a recent case study by Charteris and Smardon (2017) could assist in creating a more granular perspective of the agency afforded: sovereign, relational, ecological or new material (Charteris \& Smardon, 2017).

Analysis of the structures that were evident in the Whio community teachers' joint work suggested classification into three broad categories: structures that existed beforehand, structures that didn't and those that existed beforehand but required modification. The former could perhaps be termed Heritage structures in that they had been carried across over time (and space). In this category they were seen to include a language of educational values and vision common across the school, the 
practice of timetabling subjects, the allocation of students to a specific 'home-room' teacher. Modified structures included the use of ability groups (now shared between more than one teacher), the utilisation of SOLO taxonomy (used in an alternate context) and the removal of individual teacher desks (into a shared space). Novel structures were seen to include the practice of the 'roaming' Learning Coach, the use of synchronous and asynchronous collaborative teacher documentation, and the relationship between self-management levels and individual spatial access.

In considering organisational and pedagogical structures encountered in the case study it is important not to view them necessarily as imposed, immovable and forming a barrier between what the teachers idealised as desirable student outcomes (increased independence and self-management), and what they found themselves doing. Conspicuously it was the team of teachers themselves who had instigated particular ways of working and the structures that would enable them to do so, rather than them being externally dictated. The resultant structures had therefore largely emerged from the collaborative process itself; some replicating existing practices, some modified versions of what had gone before and others, in this context, new. As an example, the reflexive relationship between learning space and the assemblage of structures presented as pertinent in supporting the enactment of collaborative practices. Spaces and activities were articulated as mutually associated. The usage has been decided by the teachers according to levels of group size, requirements for adult intervention or supervision, and preferred levels of visibility and sound. The resultant typology had become a pedagogical structure that determined which students (and sometimes which teachers), could occupy particular spaces, and under what conditions they could do so. Explicit naming or referencing the spatial typology offered teachers and students a shared language within Whio that both were expected to adhere to.

Structure and agency have often been portrayed as opposite ends of a continuum, perhaps because simplification and binary thinking often offer a means of more simply comprehending the world we live in (Cloke \& Johnston, 2005; Gregson, 2005). For social theorist Giddens (1984) however, structure, and its relationship, particularly with agency, is considered less of a dualism and more of a duality. He warns against visualising 'structure' as external to human action, 'akin to the skeleton or morphology of an organism or to the girders of a building' (p. 16). Instead he considers that structure is 'both constraining and enabling' (p. 25) and necessarily co-constitutive. His theory of structuration holds that through their existing structures allow and enable behaviour, and so too, behaviour can potentially influence and modify structures. The infinitely cyclical manner through which this is seen to occur is described as structuration, a process that according to Archer (1982) never reaches an endpoint, and only momentarily a product. With structuration used to describe the interplay between structure and agency, formation and deformation, it echoes the notion of 'serial re-design' used by Thomson and Blackmore (2006) to describe ongoing improvement in schools.

As a theoretical framework, structuration appears to hold a useful role in professional learning regarding the enactment of teacher collaboration in ILEs. It presents as three-fold. Initially, in articulating multifarious forms of structure, be they temporal, 
spatial, organisational or linguistic. Their role when working with multiple adults and a larger cohort of students appears vital to the establishment and ongoing navigation of pedagogical approaches for both teachers and students. Secondly, there is space to incorporate, modify or innovate on existing structures, and to adapt, modify and redesign on an ongoing basis as required. Thirdly, that by viewing structures as enabling rather than constraining, their utilisation may foster approaches that leverage practices rather than limit them. Collectively these seem a useful framework to consider aspects of teachers' collaborative work as they undertake a transition from familiar to less familiar teaching and learning environments. It also responds to the theme that although much has been made of the potential of teacher collaboration in education, research detailing its enactment and reification in ILEs rather than in conceptual or theoretical form remains elusive, and a significant space for researchers to work within.

\section{Conclusion}

The requirement to work collaboratively in ILEs presents teachers with new challenges. Many stem from the need to develop pedagogical and organisational practices consistent with a team approach and larger cohort of students, rather than those previously utilised in traditional single teacher classroom settings. Determining how learning is articulated and enacted, the way space and time are navigated, and mechanisms for enabling consistency, continuity and communication, form decisional components that first create structure, and then support enactment. However, structures may both encourage as well as prevent subsequent practices. In the case illustrated here the structures designed to promote learning, self-management and agency, were considered by teachers to meet the needs of students and the vision of the school. However, the self-same structures viewed through a structure/agency dualism lens were also observed to create tensions in the way they limited the use of both time and space for teachers and students alike. As teams of teachers in ILEs develop increasingly sophisticated approaches towards teaching and learning in ILEs, structuration theory may provide a beneficial lens through which to examine the balance between levels of structure required to foster successful collaboration, and that of maintaining desirable levels of individual autonomy.

Acknowledgements Data utilised in this research was obtained adhering to the required ethical protocol of the author's host institution. All images and diagrams are the property of the author, or the author has obtained consent to use them from the appropriate copyright owner. 


\section{References}

Alterator, S. (2015). What are sustainable or generative teacher skill sets in teaching and learning within open plan learning environments? Ph.D. thesis. School of Education. La Trobe University, Bundoora, Victoria.

Alterator, S., \& Deed, C. (2013). Teacher adaptation to open learning spaces. Issues in Educational Research, 23(3), 315-330.

Archer, M. S. (1982). Morphogenesis versus structuration: On combining structure and action. The British Journal of Sociology (4), 455-483. https://doi.org/10.2307/589357.

Biggs, J. B., \& Collis, K. F. (1982). Evaluating the quality of learning: The SOLO taxonomy (Structure of the Observed Learning Outcome). New York: Academic Press.

Bradbeer, C., Byers, T., Cleveland, B., Kvan, T., Mahat, M., \& Imms, W. (2017). The 'state of play' concerning New Zealand's transition to innovative learning environments: Preliminary results from phase one of the ILETC project. Journal of Educational Leadership Policy and Practice, $32(1), 22-38$.

Butti, L. (2016). Professional relationships: Collaboration is key. The English Journal, 105(3), $12-15$.

Campbell, M., Saltmarsh, S., Chapman, A., \& Drew, C. (2013). Issues of teacher professional learning within 'non-traditional' classroom environments. Improving Schools, 16(3), 209-222. https://doi.org/10.1177/1365480213501057.

Charteris, J., \& Smardon, D. (2017). A typology of agency in new generation learning environments: Emerging relational, ecological and new material considerations. Pedagogy, Culture \& Society, 26(1), 51-68. https://doi.org/10.1080/14681366.2017.1345975.

Clandinin, D. J., \& Connelly, F. M. (1996). Teachers' professional knowledge landscapes: Teacher stories-stories of teachers-school stories-stories of schools. Educational Researcher, 25(3), 24-30. https://doi.org/10.3102/0013189x025003024.

Cleveland, B. (2011). Engaging spaces: Innovative learning environments, pedagogies and student engagement in the middle years of school. Ph.D. Unpublished, Melbourne University, Melbourne.

Cloke, P., \& Johnston, R. (2005). Deconstructing human geography's binaries. In P. Cloke \& R. Johnston (Eds.), Spaces of geographical thought. London: SAGE.

Cox, P., \& Edwards, D. (2014). Restructuring teaching and learning in open-plan schools. In V. Prain, P. Cox, C. Deed, D. Edwards, C. Farrelly, M. Keefe, V. Lovejoy, L. Mow, P. Sellings, B. Waldrip, \& Z. Yager (Eds.), Adapting to teaching and learning in open-plan schools (pp. 61-78). Rotterdam: Sense.

Deed, C., \& Lesko, T. (2015). 'Unwalling' the classroom: Teacher reaction and adaptation. Learning Environments Research (18), 217-231. https://doi.org/10.1007/s10984-015-9181-6.

Deed, C., Lesko, T., \& Lovejoy, V. (2014). Teacher adaptation to personalized learning spaces. Teacher Development, 18(3), 369-383. https://doi.org/10.1080/13664530.2014.919345.

Donohoo, J. (2017). Collective teacher efficacy research: Implications for professional learning. Journal of Professional Capital and Community, 2(2), 101-116. https://doi.org/10.1108/JPCC10-2016-0027.

Dovey, K., \& Fisher, K. (2014). Designing for adaptation: The school as socio-spatial assemblage. The Journal of Architecture, 19(1), 43-63.

Eells, R. J. (2011). Meta-analysis of the relationship between collective teacher efficacy and student achievement. Ph.D., Loyola University, Chicago. Retrieved from http://ecommons.luc.edu/luc_ diss $/ 133$.

Fisher, K. (2005). Linking pedagogy and space: Proposed planning principles. Retrieved from http:// www.eduweb.vic.gov.au/edulibrary/public/assetman/bf/Linking_Pedagogy_and_Space.pdf.

Forte, A. M., \& Flores, M. A. (2013). Teacher collaboration and professional development in the workplace: A study of Portuguese teachers. European Journal of Teacher Education, 37(1), 91-105. https://doi.org/10.1080/02619768.2013.763791. 
Fullan, M., \& Langworthy, M. (2014). A rich seam: How new pedagogies find deep learning. Retrieved from http://www.michaelfullan.ca/wp-content/uploads/2014/01/3897.Rich_Seam_ web.pdf.

Giddens, A. (1984). The constitution of society. Cambridge: Polity.

Goddard, Y., L., Goddard, R., D., \& Tschannen-Moran, M. (2007). A theoretical and empirical investigation of teacher collaboration for school improvement and student achievement in public elementary schools. Teachers College Record, 109(4), 877-896.

Gray, B. (1989). Collaborating: Finding common ground for multiparty problems. San Francisco: Jossey-Bass.

Gregson, N. (2005). Agency: Structure. In P. Cloke \& R. Johnston (Eds.), Spaces of geographical thought. London: Sage.

Hargreaves, A., \& O'Connor, M. T. (2017). Cultures of professional collaboration: Their origins and opponents. Journal of Professional Capital and Community, 2(2), 74-85. https://doi.org/10. 1108/JPCC-02-2017-0004.

Hattie, J. (2015). What works best in education: The politics of collaborative expertise. Retrieved from https://www.pearson.com/hattie/solutions.html.

Hoekstra, A., Korthagen, F., Brekelmans, M., Beijaard, D., \& Imants, J. (2009). Experienced teachers' informal workplace learning and perceptions of workplace conditions. Journal of workplace learning, 21(4), 276-298. https://doi.org/10.1108/13665620910954193.

Lieberman, A., \& Miller, L. (1990). The social realities of teaching. In A. Lieberman (Ed.), Schools as collaborative cultures: Creating the future now. New York: The Falmer Press.

Little, J. W. (1990). The persistence of privacy: Autonomy and initiative in teachers' professional relations. Teachers College Record, 91(4), 509-536.

Mattessich, P. W., Murray-Close, M., \& Monsey, B. R. (2001). Collaboration: What makes it work. A review of research literature on factors influencing successful collaboration (2nd ed.). Saint Paul, MN: Fieldstone Alliance.

McGregor, J. (2003). Making spaces: Teacher workplace topologies. Pedagogy, Culture \& Society, 11(3), 353-377. https://doi.org/10.1080/14681360300200179.

Ministry of Education. (2011). The New Zealand school property strategy 2011-2021. Retrieved from http://www.minedu.govt.nz/NZEducation/EducationPolicies/Schools/SchoolOperations/ / media/MinEdu/Files/EducationSectors/PrimarySecondary/PropertyToolbox/StateSchools/Sch oolPropertyStrategy201121.pdf.

Ministry of Education. (2016). The impact of physical design on student outcomes. Retrieved from http://www.education.govt.nz/assets/Documents/Primary-Secondary/Property/School-propertydesign/Flexible-learning-spaces/FLS-The-impact-of-physical-design-on-student-outcomes.pdf.

OECD. (2013). Innovative learning environments. Educational Research and Innovation. https:// doi.org/10.1787/9789264203488-en.

Peterson, N. L. (1991). Interagency collaboration under Part H: The key to comprehensive, multidisciplinary, coordinated infant/toddler intervention services. Journal of Early Intervention, 15(1), 89-105.

Riessman, C. K. (2008). Narrative methods for the human sciences. Thousand Oaks, CA: Sage.

Saltmarsh, S., Chapman, A., Campbell, M., \& Drew, C. (2015). Putting "structure within the space": Spatially un/responsive pedagogic practices in open-plan learning environments. Educational Review, 67(3), 315-327. https://doi.org/10.1080/00131911.2014.924482.

Stake, R. E. (1995). The art of case study. Thousand Oaks: Sage.

Stoll, L., Bolam, R., McMahon, A., Wallace, M., \& Thomas, S. (2006). Professional learning communities: A review of the literature. Journal of Educational Change, 7(4), 221-258.

Thomson, P., \& Blackmore, J. (2006). Beyond the power of one: Redesigning the work of school principals. Journal of Educational Change, 7, 161-177. https://doi.org/10.1007/s10833-0060003-6.

Thomson, A. M., \& Perry, J. L. (2006). Collaboration processes: Inside the black box. Public Administration Review, 20, 20-32. https://doi.org/10.1111/j.1540-6210.2006.00663.x. 
Vangrieken, K., Dochy, F., Raes, E., \& Kyndt, E. (2015). Teacher collaboration: A systematic review. Educational Research Review, 15, 17-40. https://doi.org/10.1016/j.edurev.2015.04.002.

Wood, D. J., \& Gray, B. (1991). Toward a comprehensive theory of collaboration. The Journal of Applied Behavioral Science, 27(2), 139-162. https://doi.org/10.1177/0021886391272001.

Woolner, P., Clark, J., Laing, K., Thomas, U., \& Tiplady, L. (2012). Changing spaces: Preparing students and teachers for a new learning environment. Children Youth and Environments, 22(1), $52-74$.

Chris Bradbeer (NZ) is an Honorary Research Fellow (part-time), on the Innovative Learning Environments \& Teacher Change Project 2016-2020 being run by The University of Melbourne, an Associate Principal at Stonefields School in Auckland, Chair of Learning Environments Australasia and currently completing a Ph.D. focusing on the nature of teacher collaboration in Innovative Learning Environments in New Zealand primary schools.

Open Access This chapter is licensed under the terms of the Creative Commons Attribution 4.0 International License (http://creativecommons.org/licenses/by/4.0/), which permits use, sharing, adaptation, distribution and reproduction in any medium or format, as long as you give appropriate credit to the original author(s) and the source, provide a link to the Creative Commons license and indicate if changes were made.

The images or other third party material in this chapter are included in the chapter's Creative Commons license, unless indicated otherwise in a credit line to the material. If material is not included in the chapter's Creative Commons license and your intended use is not permitted by statutory regulation or exceeds the permitted use, you will need to obtain permission directly from the copyright holder. 